\title{
GEOSTATISTICAL AND CLUSTER ANALYSIS OF EARTHQUAKES IN THE PHILIPPINES
}

\author{
${ }^{1}$ Dilig, Ivy Jean A., ${ }^{1}$ San Juan, Wilbert Ian M. \\ ${ }^{1}$ Department of Geodetic Engineering, University of the Philippines Diliman - \\ (ivy_jean.dilig, wmsanjuan)@up.edu.ph

\section{Commission IV}

KEY WORDS: earthquakes, hot spots, geostatistics, clusters, temporal analysis

\begin{abstract}
:
The Philippine region is one of the most natural hazard-prone areas. Hazards from an earthquake event, or seismic hazards, may be addressed with the analysis of the previous occurrences across the country. This was performed by analyzing earthquake hot spots or clusters using geostatistical methods such as Getis-Ord Gi* and Anselin Local Moran's I. This study mapped the earthquake events per magnitude from 1975 to 2019, and determined the hot spots, and its patterns across the Philippine region. It also compared the results of a prediction output from a 2016 study, and performed a quick temporal analysis of the earthquakes from 1975 to 2019. This study was able to determine the earthquake hot spots, mostly in the southern provinces, and with most of which lie along the major trenches.
\end{abstract}

\section{INTRODUCTION}

\subsection{Research Problem}

Ninety percent of the earthquakes occur along the arch of the Pacific Ring of Fire, a path of active volcanoes along the Pacific Ocean. This arch consists of many meeting points of different tectonic plates, including the Philippines. (National Geographic Society, 2019)

The Philippines experiences around 3.2 earthquakes per day and an approximately $2-2.5 \mathrm{~cm} /$ year slip rate experiences from fault planes. The Philippine Fault Zone (PFZ) extends 1200 $\mathrm{km}$ across the Philippine archipelago behind the convergent boundary of the Philippine Trench and the subduction of the Philippine Sea Plate. It extends from Davao Gulf in the south, bisects the Caraga region at the Agusan River basin, crosses to Leyte and Masbate islands, and traverses Quezon province in eastern Luzon before passing through Nueva Ecija up to the Ilocos region in northwest Luzon. The northern and southern extensions of the PFZ are characterized by branching faults due to brittle terminations. These horsetail faults are indicative of the lateral propagation and further development of the PFZ. (Yumul 2008)

The patterns of the occurrences of earthquakes might help researchers, through geostatistical analysis, in addressing the effects of such phenomena. Hazard mitigation could be applied to the areas that indicate a high number of earthquake occurrences.

\subsection{Research Objectives}

The objective of the study is to map the earthquakes that occurred in the Philippines from 1975 to 2019, determine the earthquake hot spots and perform cluster analyses to identify spatial patterns.

Specifically, the study aims to perform local geostatistical methods such as Anselin Local Moran's I and Getis-Ord Gi* to analyze and understand spatial patterns of earthquakes in the Philippines. Furthermore, it aims to compare the results of the hot spots to the prediction given by a study from 2016 . Lastly, it aims for a quick temporal analysis of earthquakes from 2010 to 2019 using an optimized hot spot tool.

\subsection{Scope and Limitations}

The scope of the study is the Philippine region bounded by its nearby trenches. The study is limited to the analysis of earthquakes using its magnitudes, specifically from Magnitude 4.0 to the highest recorded magnitude from the dataset of 1975 to 2019. This study does not utilize other factors such as depth of the earthquake, declustering or removal of aftershocks in the dataset, and the assessment of a complete earthquake cycle which may need a much larger dataset.

\subsection{Related Literature}

A 2016 study from Thailand entitled "Earthquake activities in the Philippines Islands and the adjacent areas" by Pailoplee, et. al. focused on the seismic activities in the Philippine region and its neighboring countries. The authors employed the frequency-magnitude distribution model, and evaluated the possible maximum magnitude, return period, and probability of earthquake occurrence in the said area.

Figure 1 shows the areas where high magnitudes of earthquakes might occur in the next 5 or 10 years. This is indicative of the earthquake hot spots that occurred in the last 10 years. Since the study used the dataset of earthquakes of up to year 2010, this research processed the subsets of data from years 2010 to 2015 , and 2010 to 2019 , to correspond to the 'next 5 or 10 years' from Pailoplee's study. 


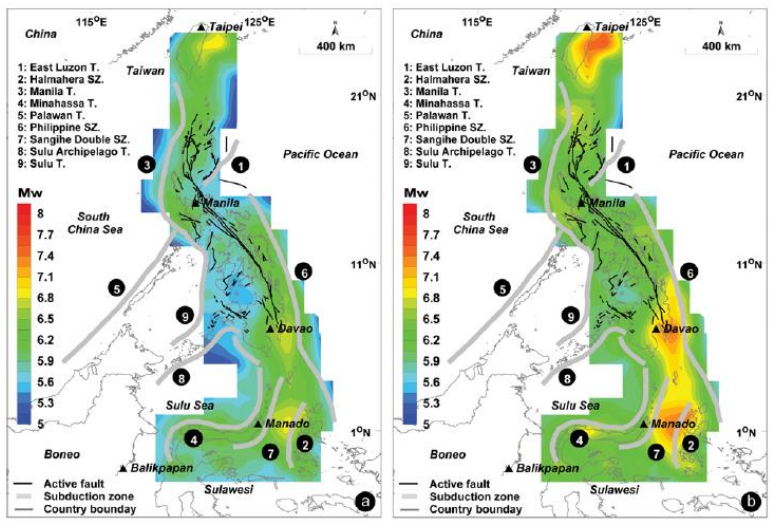

Figure 1. Map of the Philippines showing the maximum earthquake magnitude likely to be generated in each area in the next (a) 5, (b) 10 years respectively.

\section{METHODOLOGY}

The methodology for the geostatistical analysis of earthquake hot spots in the Philippines is grouped into three: Data Preprocessing, Data Processing, which focuses on the analysis of clusters, and the map preparations along with the discussion of results. Figure 2 below shows the illustration of the methodology.

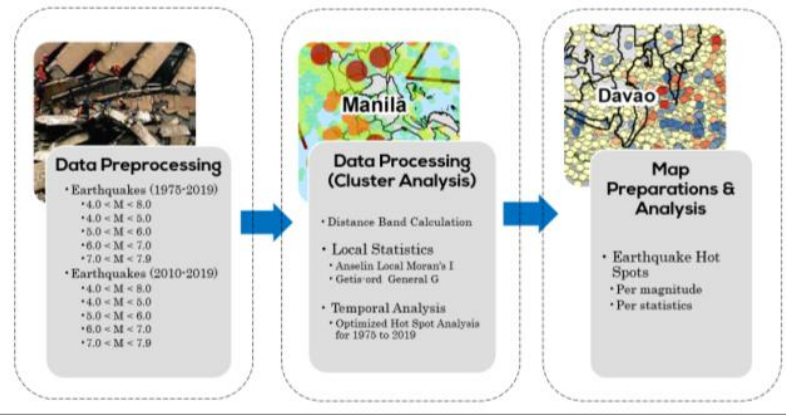

Figure 2. Methodology for Geostatistical and Cluster Analysis of Earthquakes

The preprocessing of data involves preparing the earthquake data (in CSV format) by using a simple code to extract the needed dataset from USGS. This is loaded in ArcGIS 10.2.2, with longitude and latitude as its $\mathrm{X}$ and $\mathrm{Y}$, and with magnitude as the third component. The necessary fields to use are latitude, longitude, magnitude, and date (year). The main dataset used is from 1975 to 2019. These points were then sliced according to the magnitude, namely: 4.0-4.9, 5.0-5.9, 6.0-6.9, and 7.0-7.9. A subset of the dataset was exported that uses the years 2010 to 2019 . Similarly, these points were sliced according to magnitude.

The faults and trenches in the Philippine region were acquired from Philippine Institute of Volcanology and Seismology (PHIVOLCS).

For the cluster analysis, the distance band or threshold distance for every set of magnitude points was calculated using the available tool in ArcGIS. Table 1 below shows the distance bands used to process the hot spot analysis.

\begin{tabular}{|c|c|c|}
\hline Dataset & Magnitude & $\begin{array}{c}\text { Distance Band (in } \\
\text { meters) }\end{array}$ \\
\hline \multirow{4}{*}{1975 to 2019} & $4.0-4.9$ & 7000 \\
\cline { 2 - 3 } & $5.0-5.9$ & 13000 \\
\cline { 2 - 3 } & $6.0-6.9$ & 58000 \\
\hline \multirow{4}{*}{2010 to 2019} & $7.0-7.9$ & 150000 \\
\cline { 2 - 3 } & $4.0-4.9$ & 12000 \\
\cline { 2 - 3 } & $5.0-5.9$ & 30000 \\
\cline { 2 - 3 } & $6.0-6.9$ & 180000 \\
\hline
\end{tabular}

Table 1. Distance Bands used for Hot Spot Analysis

Global statistics generally provide a summary of the pattern or trend over the whole dataset, while local statistics identify spatial variations in the relationship between variables that are useful for the identification of hot spots or particular clusters. This research focuses on the local statistics methods, namely Getis-Ord Gi* and Anselin Local Moran's I. Furthermore, the conceptualization of spatial relationship used in this study is the fixed distance band, with Euclidean distance as the distance method.

The hot spot analysis using Getis-Ord Gi* was used for every set of magnitude, similar to the analysis using Anselin Local Moran's I; thereby generating eight (8) maps of earthquake hot spots in the Philippines. Map preparations and analysis were done after processing of the datasets. Significant hot spots and patterns were noted for every map created.

This entire procedure was repeated for the data subset (2010 to 2019), but all magnitudes were considered in using the two methods. A distance band of 11000 meters was used in processing the hot spots. The results were then compared from the study created by researchers from Chulalongkorn University in Thailand, as mentioned in Section 1.4. Their study included a map of the maximum earthquake magnitude likely to be generated within the next 5 and 10 years. Since the dataset used in the study is only up to 2010 , the data subset processed for comparison is from 2010 to 2019, which corresponds to the 'next 5 and 10 years' in the study.

Lastly, the temporal analysis of earthquake hot spots was processed using the Optimized Hot Spot Analysis tool (GetisOrd Gi* statistic) for the years 1975 to 2019.

\section{RESULTS AND DISCUSSION}

\subsection{Datasets Used}

The following images and maps are the datasets used in this study.

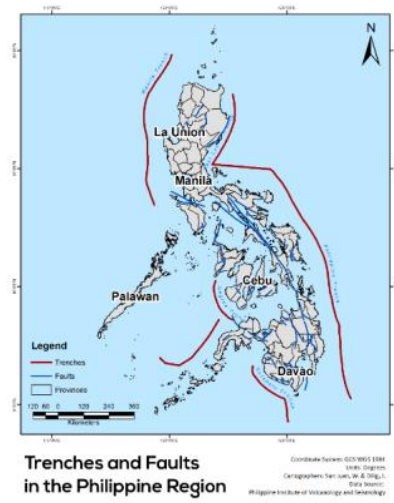

Figure 3. Trenches and Faults in the Philippine Region 
There are around eighty (80) faults, and seven (7) trenches in the region. One of the most remarkable is the Philippine Trench, which is the third deepest point in the world with its Galathea depth of 10.54 kilometers below sea level.

\subsection{Distribution of Earthquakes in the Philippines}

The next map shows the distribution of earthquakes in the Philippines from 1975 to 2019.

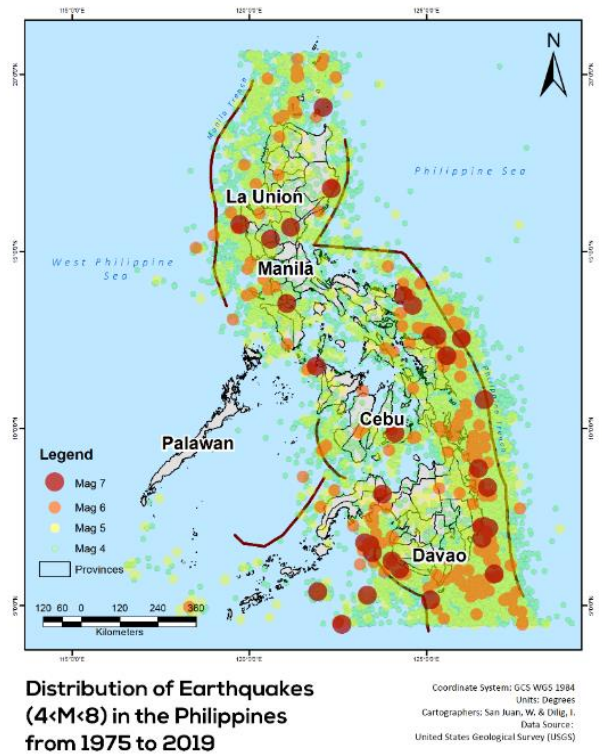

Figure 4. Distribution of Earthquakes in the Philippines from 1975 to 2019

This dataset comprises more than 16,000 points with attributes such as latitude, longitude, magnitude, and date occurred.

The next set of images shows the distribution of earthquakes, per magnitude.

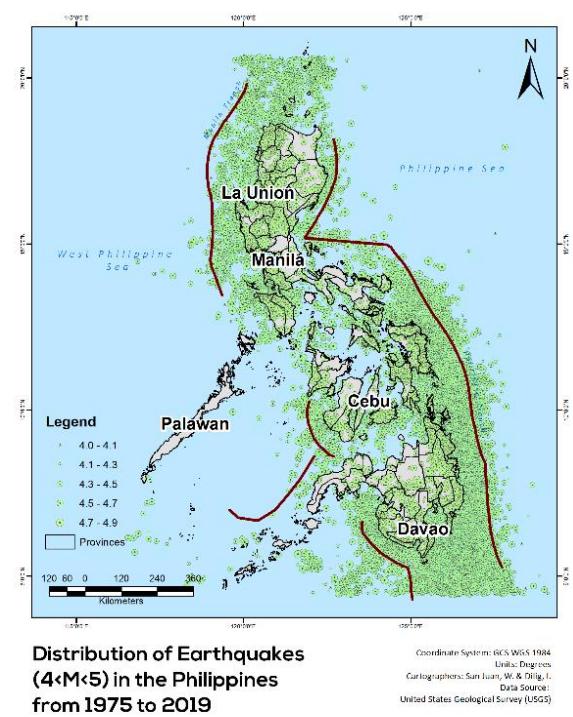

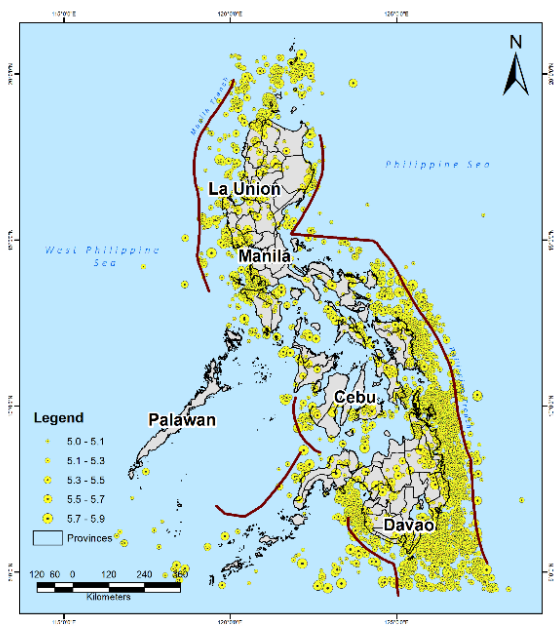

Distribution of Earthquake $(5<M<6)$ in the Philippines from 1975 to 2019

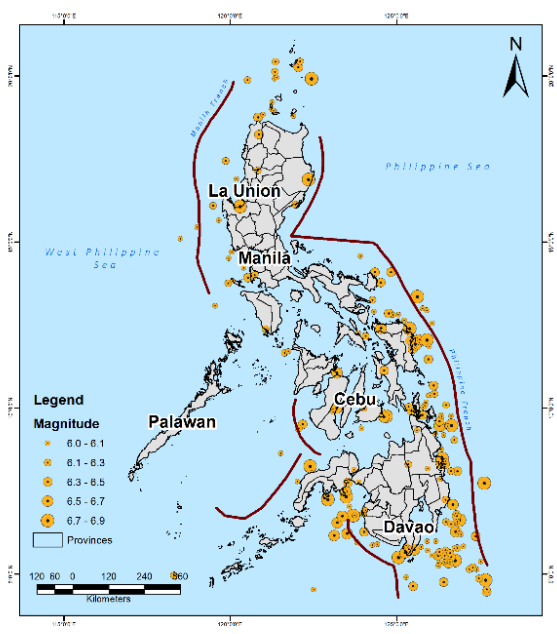

Distribution of Earthquakes

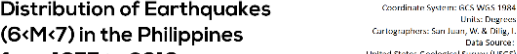

from 1975 to 2019

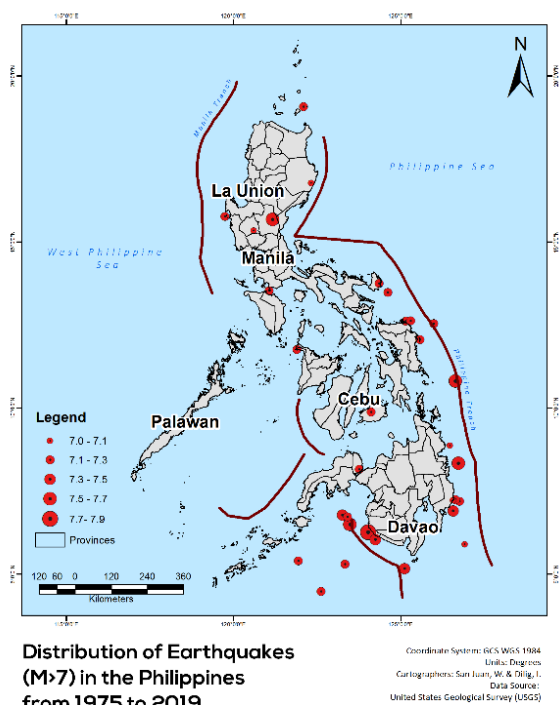

from 1975 to 2019

Figure 5. Distribution of Earthquakes (per magnitude) in the Philippines from 1975 to 2019 
It can be noticed that the distribution of earthquakes mostly lie in the trenches, specifically in the Philippine Trench. The highest magnitude ever recorded from 1975 to 2019 was Mag. 7.6 in Mindanao last Aug. 1976. Mag. 7.7 in Nueva Ecija, Luzon last July 1990 follows this event, which severely damaged a number of buildings and killed hundreds.

\subsection{Earthquake Hot Spots in the Philippines (Using Getis- Ord Gi*)}

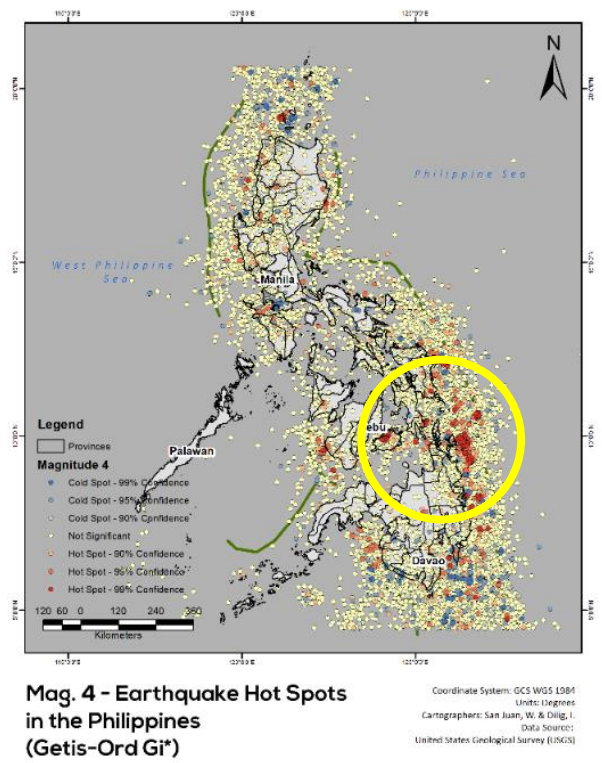

Figure 6. Mag.4-Earthquake Hot Spots in the Philippines from 1975 to 2019

In the map shown above, there exists a hot spot (in red) near the province of Surigao del Norte. The spot is also seen along the Philippine Trench. Meanwhile, there is generally a number of cold spots in the northern region of the country. The next map shows the Magnitude 5.0 - Earthquake Hot Spots in the Philippines.

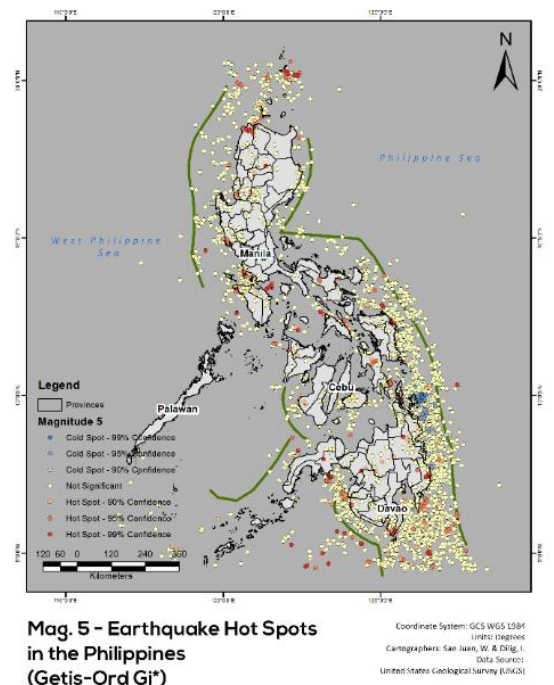

Figure 7. Mag.5-Earthquake Hot Spots in the Philippines from 1975 to 2019

This map shows that there are hot spots located in the areas of Ilocos Norte, Batanes, Mindoro, Samar, and Davao Oriental.
For the Magnitude 6.0 - Earthquake Hot Spots, it can be seen, as shown below, that a hot spot is viewed in the province of Eastern Samar, almost falling along the Philippine Trench.
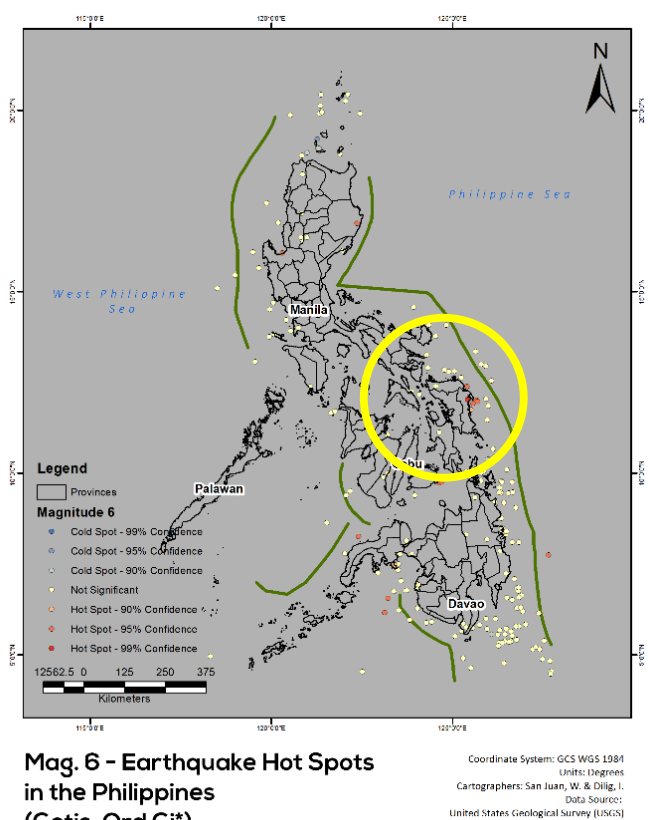
(Getis-Ord Gi*)

Figure 8. Mag.6-Earthquake Hot Spots in the Philippines

Lastly, the Mag.7 hotspots are located near the province of Sultan Kudarat. It is worth noting that this spot falls along the Cotabato Trench. No other spots, hot or cold spot, were detected across the region.

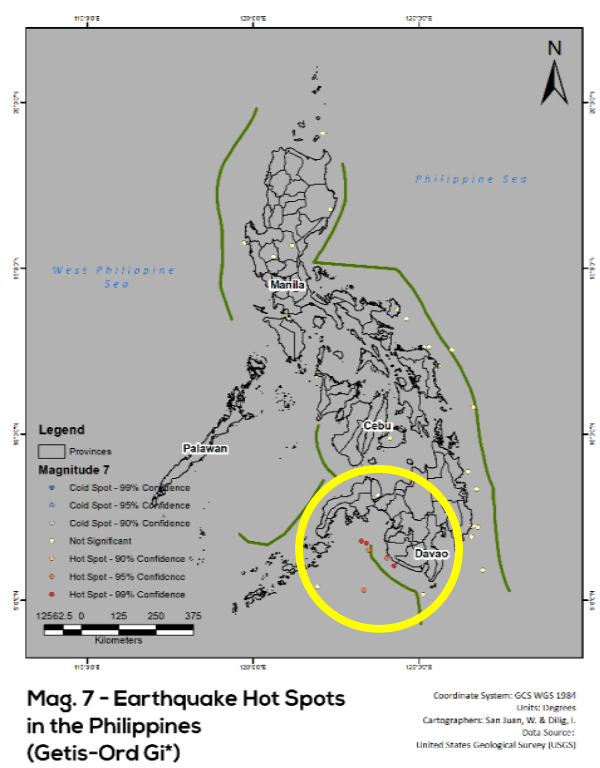

Figure 9. Mag.7-Earthquake Hot Spots in the Philippines

\subsection{Earthquake Hot Spots in the Philippines (Using Anselin Local Moran's I)}

The same set of magnitudes are repeatedly processed for another local geostatistic called Anselin Local Moran's I. This method determines clusters and outliers by categorizing the input dataset to the following groups: High-High cluster 
(highly-valued points surrounded with fellow highly-valued points, thus indicating a hot spot), Low-Low cluster (indicates a cold spot), High-Low outlier (highly-valued points but surrounded with lowly-valued points), Low-High outlier (lowly-valued points surrounded with highly-valued points), and insignificant data.

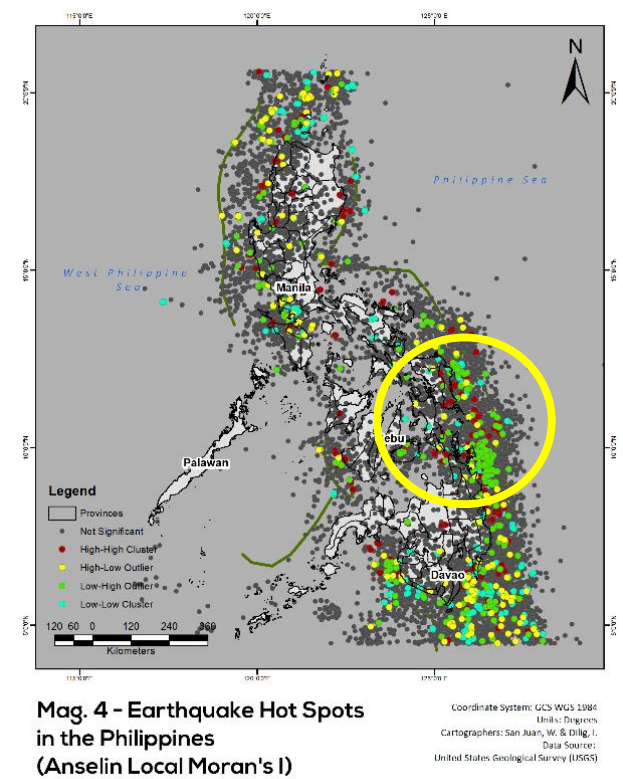

Figure 10. Mag.4-Earthquake Clusters in the Philippines

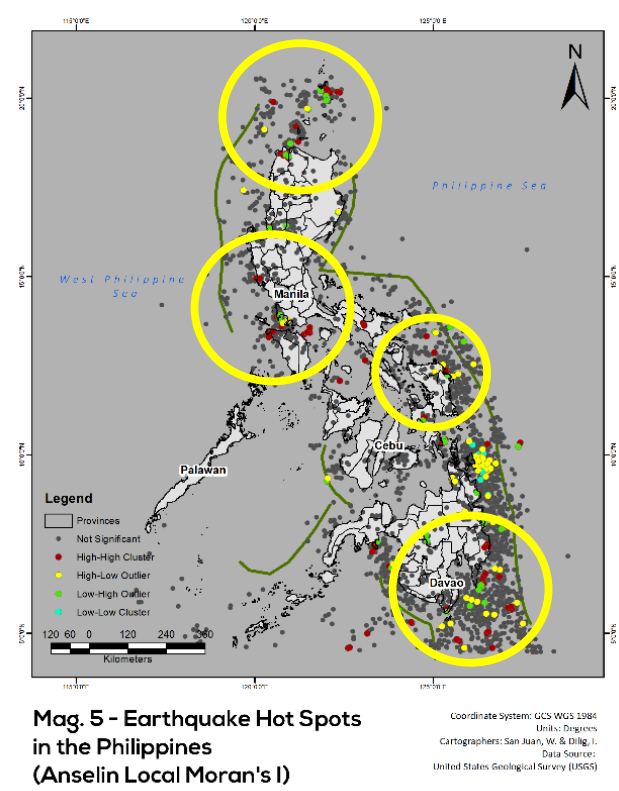

Figure 11. Mag.5-Earthquake Clusters in the Philippines

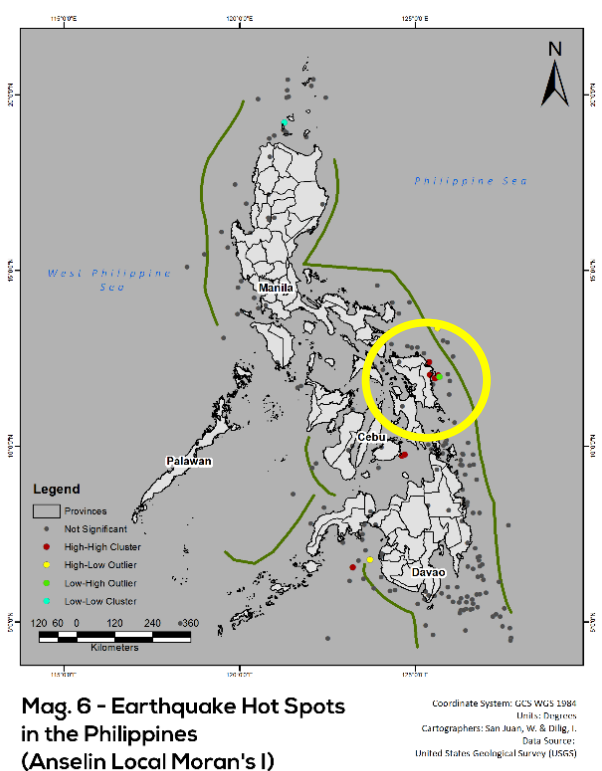

Figure 12. Mag.6-Earthquake Clusters in the Philippines

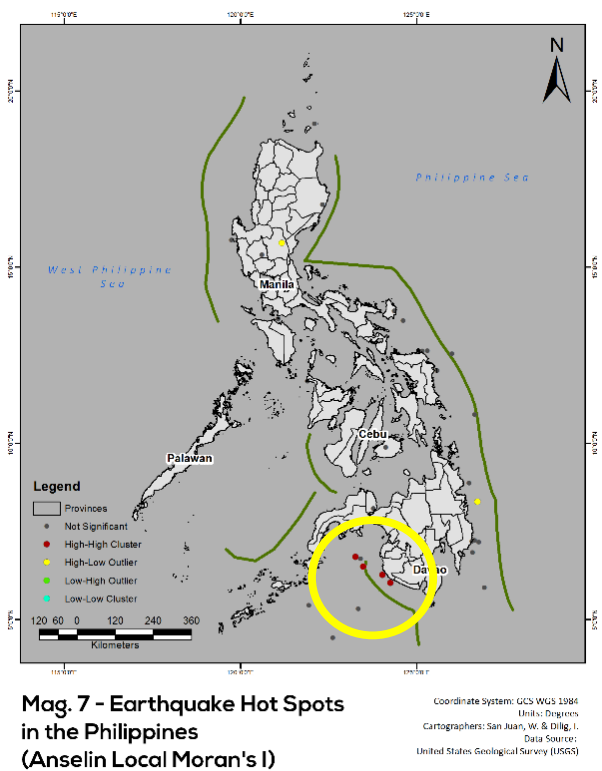

Figure 13. Mag.7-Earthquake Clusters in the Philippines

The maps shown illustrate the results of the hot spots (per magnitude) in the Philippines from 1975 to 2019, using Anselin Local Moran's I. High-valued clusters of earthquakes (red points), or hot spots, are seen in the areas/provinces previously mentioned in the results from Getis-Ord Gi*. There are also low-valued clusters (light blue points), or cold spots, present in almost the same areas from the results of the first statistic used. Low-High and High-Low Outliers, as well as insignificant points, are also present after processing.

\subsection{Comparison of Prediction Outputs}

Figure 14 shows the map of the Philippine Islands and the adjacent areas showing the maximum earthquake magnitude likely to be generated in each area in the next ten (10) years, according to the study of Pailoplee S. 


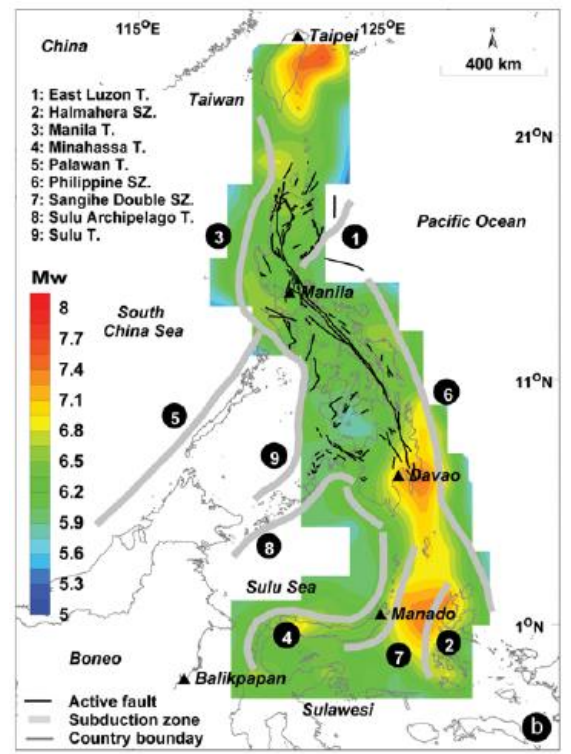

Figure 14. Maximum Earthquake Magnitude likely to be generated within 10 years

Since the study used an earthquake dataset of up to 2010, the researchers processed the 2010 to 2019 data to identify the clusters and compare it with the result. Figure 15 and 16 show the earthquake hot spots in the Philippines from 2010 to 2019 (Magnitudes 4.0 to 7.9 ) using Getis-Ord Gi* and Anselin Local Moran's I.

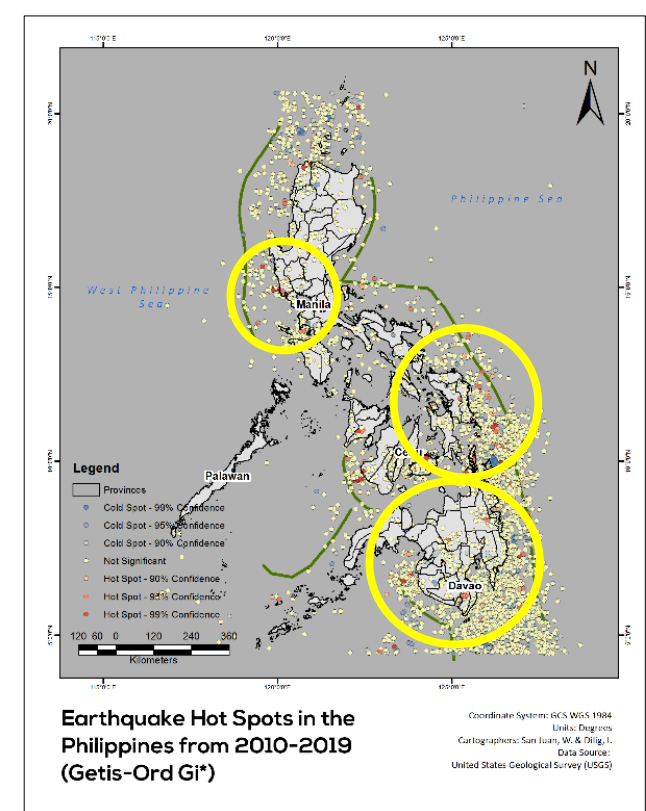

Figure 15. Earthquake Hot Spots in the Philippines from 2010 to 2019 (Getis-Ord Gi*)

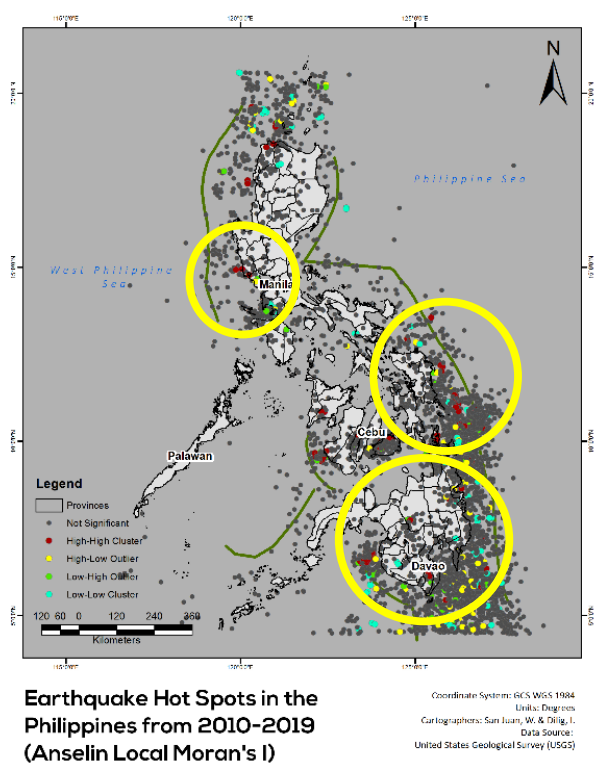

Figure 16. Earthquake Hot Spots in the Philippines from 2010 to 2019 (Anselin Local Moran's I)

It can be noticed that there is a similar pattern from the result of the mentioned study to the hot spots from 2010 to 2019 . Most of the high-magnitude earthquake clusters fall within the southern part of the Philippine region.

The next maps show the same procedure but for the dataset 2010 to 2015 , i.e, within five (5) years.

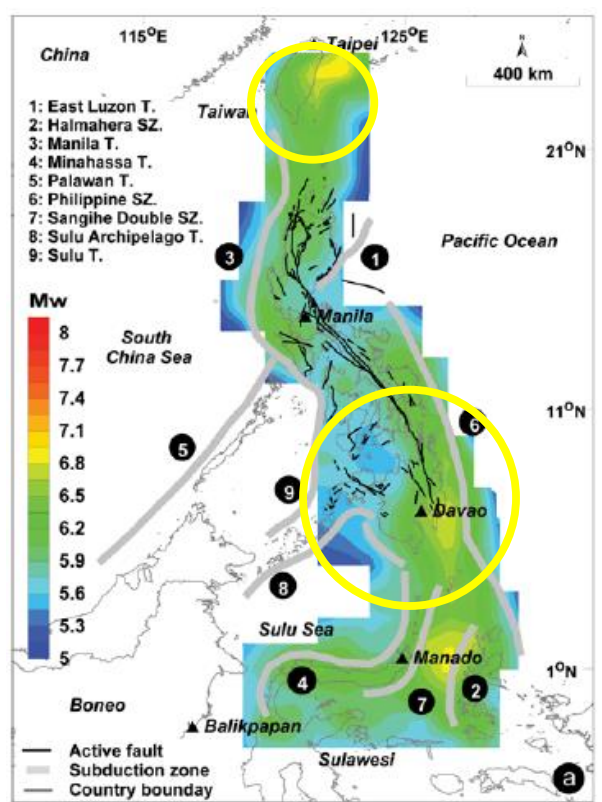

Figure 17. Maximum Earthquake Magnitude likely to be generated within 5 years

Shown in Figure 18 are the earthquake hot spots from 2010 to 2015. 


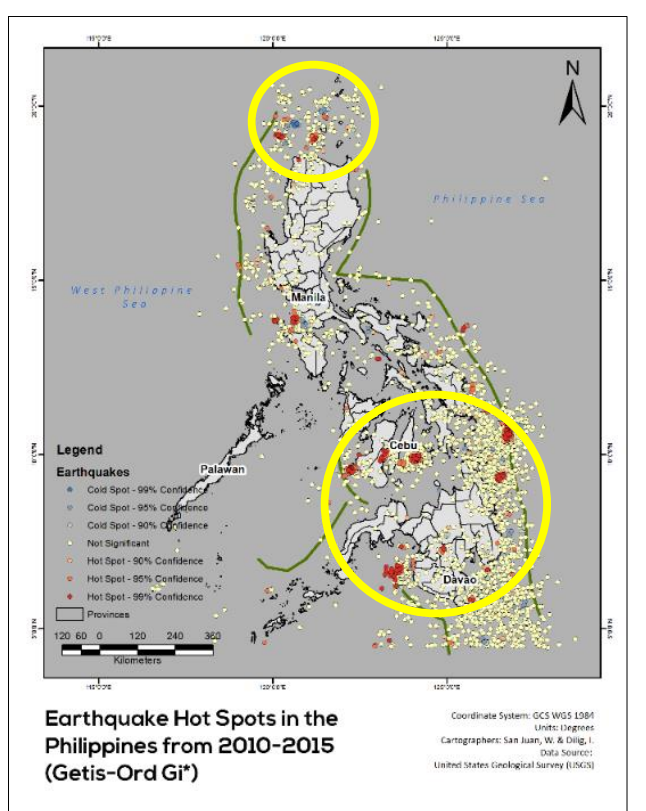

Figure 18. Earthquake Hot Spots in the Philippines from 2010 to 2015 (Getis-Ord Gi*)

The areas emphasized in yellow circles show the hot spots from 2010 to 2015. These patterns can be seen in the prediction output of the study (green to yellow areas).

\subsection{Temporal Analysis of Earthquake Hot Spots}

The following images show the progression of hot spots from the following set of years: 1975 to 1983,1983 to 1992,1992 to 2001,2001 to 2010 , and 2010 to 2019 .

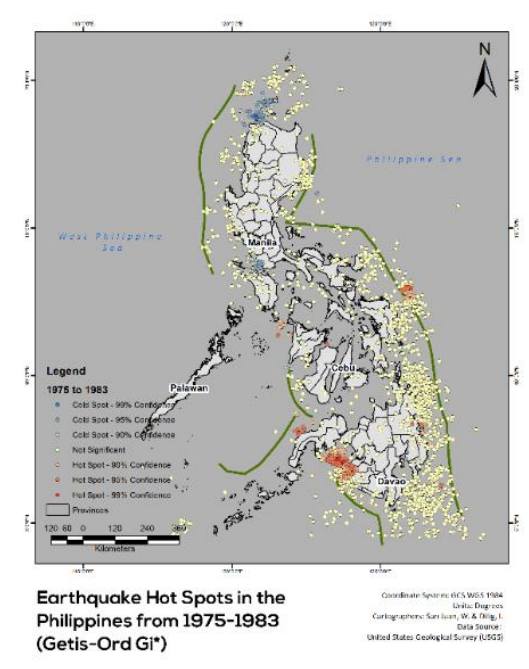

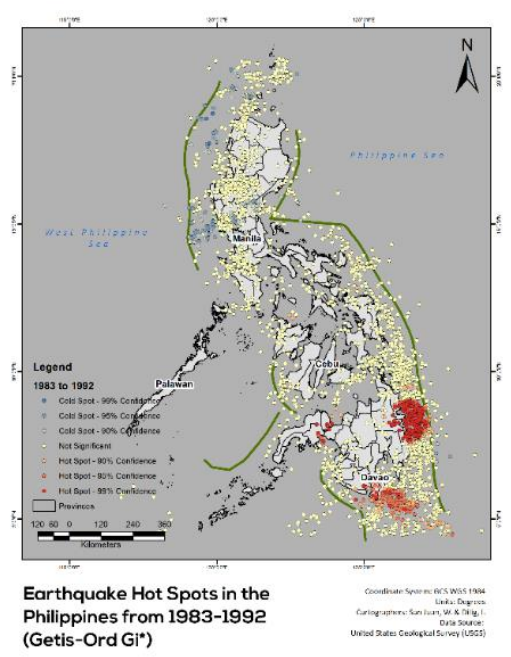

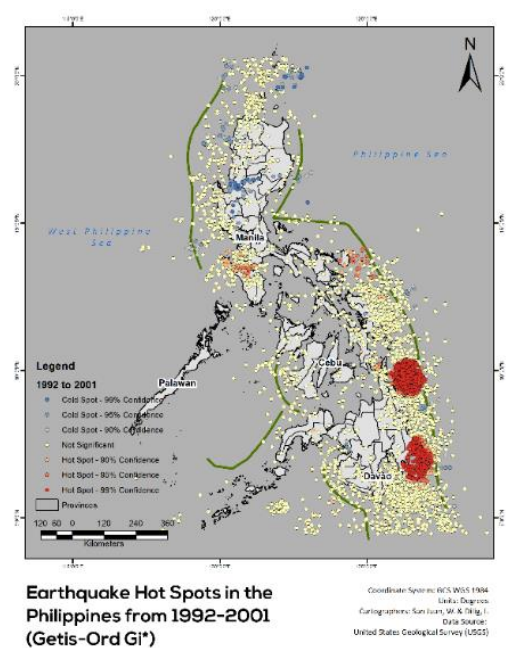
(Getis-Ord Gi*)

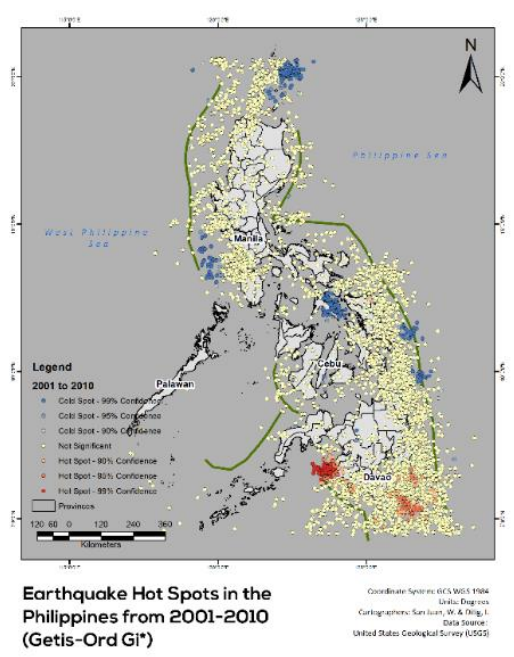




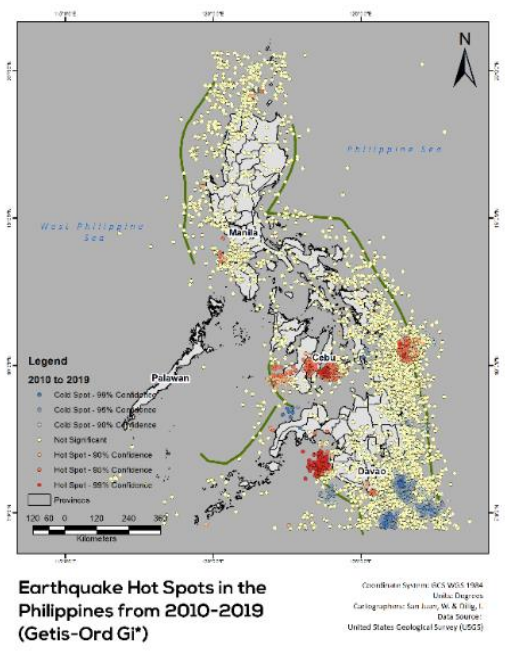

Figure 19. Temporal Analysis of Earthquake Hot Spots in the Philippines from 2010 to 2019

From the results of the Getis-Ord Gi* statistic, the hot spots generally lie in the southern part of the country. Also, a trend of cold spots is observed in the northern part. There is no broadening of the clusters, except that their locations always lie on either the Philippine Trench or Cotabato Trench.

In summary, the table below lists the earthquake hot spots per magnitude in the Philippine region.

\begin{tabular}{|c|c|}
\hline Magnitude & Earthquake Hotspot \\
\hline 4.0 & Surigao del Norte (Region XIII) \\
\hline 5.0 & $\begin{array}{c}\text { Ilocos Norte (Region I), Batanes } \\
\text { (Region II), Mindoro (Region IV), } \\
\text { Samar (Region VIII), and Davao } \\
\text { Oriental (Region XI) }\end{array}$ \\
\hline 6.0 & Eastern Samar (Region VIII) \\
\hline 7.0 & Sultan Kudarat (Region XII) \\
\hline
\end{tabular}

Table 2. Earthquake Hot Spots per Magnitude

Most of these provinces are in the southern region and the hot spots lie near or along the major trenches found in the Philippines.

\section{CONCLUSIONS AND RECOMMENDATIONS}

\subsection{Conclusions}

Earthquake hot spots and clusters in the Philippines were detected and mapped using local geostatistical methods such as Anselin Local Moran's I and Getis-Ord Gi*. Similar patterns of clusters were seen from both methods.

The hot spots and clusters of earthquake mapped in this study mostly fall along the trenches in the Philippine region, specifically in the Philippine Trench. These trenches prompt the movement over an area of the plate interface that consequently trigger earthquakes.

Prediction from Pailoplee's study proves the hot spot occurrences of earthquakes from 2010-2015, and 2010-2019 as mapped in this study.

\subsection{Recommendations}

The researchers recommend performing the processing of earthquake data by focusing not only on the magnitude, but also on the depth of the earthquake. This factor may provide additional input to the analysis of clusters.

In addition, the researchers recommend assessing clusters of earthquakes in the neighboring countries as these might affect the overall analysis.

\section{REFERENCES}

Pailoplee S., Boonchaluay, N. 2016. Earthquake activities in the Philippines Islands and the adjacent areas. Geosciences Journal. DOI 10.1007/s12303-016-0017-x

Luz, L., Manalili, M. A. 2016. Exploring Historical Earthquakes in the Philippines: A Geostatistical and SpaceTime Approach.

Al-Ahmadi, K., Al-Amri A., See, L. 2014. A spatial statistical analysis of the occurrence of earthquakes along the Red Sea floor spreading: Clusters of seismicity. Arabian Journal of Geosciences. DOI 10.1007/s12517-013-0974-6

Yumul, G., Dimalanta, C., Maglambayan, V., Marquez, E. 2008. Tectonic setting of a composite terrane: A review of the Philippine island arc system. Geosciences Journal 12, 7-17. DOI: $10.1007 / \mathrm{s} 12303-008-0002-0$

Demirci, A., Karaburun, A. 2016. Spatio-temporal cluster analysis of the earthquake epicenters in Turkey and its surrounding area between 1900 and 2014. International Journal of Research in Earth and Environmental Sciences. 